\title{
Penerapan Algoritma Apriori Untuk Menentukan Persediaan Peralatan Dan Mesin
}

\author{
Debora Kesia Batubara ${ }^{1}$, Nining Suryani ${ }^{2}$, Duwi Cahya Putri Buani ${ }^{3}$ \\ ${ }^{1}$ Sistem Informasi, Sekolah Tinggi Manajemen Informatika dan Komputer Nusa Mandiri \\ 2,3 Sistem Informasi, Universitas Bina Sarana Informatika, Teknik Informatika, Sekolah Tinggi \\ Manajemen Informatika \\ 1'deborabtb9876@gmail.com ,2nining.nns@bsi.ac.id ,3duwi.dcp@nusamandiri.ac.id
}

\begin{abstract}
The DKI Jakarta Regional Asset Management Agency (BPAD) is a State Agency that regulates budget costs for many types of assets in the DKI Jakarta area. One type of budget is for equipment and machinery that are needed annually. The local budget so far has not focused on the equipment and machinery needed. This is needed in order to be able to minimize the budget and focus on the equipment and machinery needed each year. In this case Data Mining can be applied to find information from the dataset. In order to know the Equipment and Machines that are most needed each year, searching for information on the dataset can be done by one of the Data Mining methods, namely the A priori Algorithm by looking for patterns of relationships in a dataset. If you know the equipment and machinery that are most needed each year, BPAD can focus the budget on the goods most needed and can find out which SKPD need more equipment and machinery each year.
\end{abstract}

Keywords: BPAD, Data Mining, Algoritma Apriori.

Abstraksi: Badan Pengelolaan Aset Daerah (BPAD) DKI Jakarta adalah Instansi Negara yang mengatur biaya anggaran untuk banyak jenis aset di daerah DKI Jakarta. Salah satu jenis anggaran yang ada ialah untuk Peralatan dan Mesin yang tiap tahunnya dibutuhkan. Anggaran daerah sejauh ini belum berfokus pada Peralatan dan Mesin yang dibutuhkan. Hal ini diperlukan agar dapat lebih meminimalisir anggaran dan berfokus kepada Peralatan dan Mesin yang dibutuhkan tiap tahunnya. Dalam hal ini Data Mining dapat diterapkan untuk mencari informasi dari dataset. Agar dapat mengetahui Peralatan dan Mesin yang paling dibutuhkan tiap tahunnya, pencarian informasi pada dataset dapat dilakukan dengan salah satu metode Data Mining yaitu Algoritma Apriori dengan mencari pola hubungan dalam sebuah dataset. Jika mengetahui Peralatan dan Mesin yang paling dibutuhkan tiap tahunnya maka BPAD dapat memfokuskan anggaran pada barang yang paling dibutuhkan dan dapat mengetahui SKPD mana yang lebih membutuhkan Peralatan dan Mesin setiap tahunnya..

Kata Kunci: BPAD, Data Mining, Algoritma Apriori.

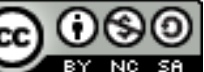

This is an open access article distributed under the Creative Commons Attribution License, which permits unrestricted use, distribution, and reproduction in any medium, provided the original work is properly cited. (02019 by author and IJSE-Indonesian Journal on Software Engineering.

\section{A. PENDAHULUAN}

Pemerintahan di Indonesia terdiri dari beberapa unit kerja atau bagian yang bergerak pada bidangnya masing-masing. Semua unit kerja bisa berjalan dengan baik jika adanya staff atau pegawai dan adanya peralatan yang memumpuni untuk meningkatkan kinerja pegawai. Seiring dengan berjalannya waktu, tiap tahunnya sebuah unit kerja pasti membutuhkan lebih banyak persediaan stok peralatan dan mesin. Karena itu dibutuhkan pendataan untuk tiap peralatan dan mesin yang ada dalam unit kerja pemerintahan. Pendataan dilakukan untuk mengetahui berapa jumlah anggaran yang harus keluarkan. Dan untuk memfokuskan pada stok barang yang memang paling dibutuhkan tiap tahunnya. Menurut penelitian yang dilakukan (Wahyuni et al., 2017) tentang implementasi data mining untuk menentukan stok barang dengan algoritma apriori dapat membantu menentukan pola persediaan stok. Selanjutnya ada penelitian yang dilakukan 
oleh (Ependi \& Putra, 2019) untuk memprediksi persediaan barang dengan algoritma apriori dapat membantu menganalisis pola keterhubungan antar stok, dan untuk mengetahui produk yang paling banyak dibeli. Lalu ada penelitian yang dilakukan oleh (Kennedi Tampubolon, Hoga Saragih, 1966) tentang implementasi data mining untuk sistem persediaan alat-alat kesehatan, untuk menentukan pola kombinasi itemsetdan mempercepat proses pembentukan kecenderungan pola kombinasi itemset.

Setiap peralatan dan mesin yang dibeli dengan anggaran pemerintahan harus dicatat pengesahannya, kapan pengadaan barang tersebut, penggunaannya, dan juga kondisi barangnya. Tiap barangnya pun harus di data asalsumber perolehannyamisalnya dari APBD (AnggaranPendapatan dan Belanja Daerah), pembangunan, hibah Guna Usaha, Sekolahdan BOP (Biaya Overhead Pabrik), dan masih banyak lagi yang sah keberadaannya. Data seperti ini dapat diolah dengan data mining, dan menggunakan metode tertentu sesuai dengan tipe datanya, agar mendapatkan hasil perhitungan yang bisa digunakan oleh pihak BPAD (Badan Pengelola Aset Daerah) untuk membantu mengetahui perlatan dan mesin apa saja yang paling diperlukan tiaptahunnya pada suatu instansi. Pihak BPAD pun dapat mengalokasikan dana sesuai dengan kebutuhan yang diperlukan. Pendataan yang kurang cermat dalam mengelola data menjadi masalah utama saat ini. Khususnya untuk data peralatan dan mesin, karena bisa mengakibatkan pengalokasian dana itu tidak berfokus pada hal yang paling dibutuhkan tiap tahunnya. Dari permasalahan yang ada, maka penulis bermaksud untuk membantu mempermudah pihak BPAD dalam mengelola data dengan melakukan perhitungan persediaan peralatan dan mesin pada Sudin Perpustakaan dan Kearsipan. Supaya pihak BPAD dapat memfokuskan biaya anggaran untuk peralatan dan mesin yang paling dibutuhkan setiap tahunnya.

\section{B. TINJAUAN PUSTAKA}

Data Mining adalah suatu proses menemukan hubungan yang berarti, pola, dan kecenderungan dengan memeriksa dalam sekumpulan besar data yang tersimpan dalam penyimpanan dengan menggunakan teknik pengenalan pola seperti teknik statistik dan matematika(Budiantara \& Budihartanti, 2020).

Data mining juga dibagi menjadi beberapa teknik berdasarkan tugasnya (Azwar, 2015), diantaranya yaitu :

a. Deskripsi

b. Terkadang analis/peneliti ingin mendes-kripsikan pola dan trend yang tersimpan dalam data.

c. Estimasi

d. Estimasi mirip dengan klasifikasi, kecuali variabel tujuan yang lebih kearah numeric daripada kategori. Misalnya, akan dilakukan estimasi tekanan darah systolic dari pasien rumah sakit berdasarkan umur pasien, jenis kelamin, indeks berat badan, dan level sodium darah.

e. Prediksi

Prediksi memiliki kemiripan dengan estimasi dan klasifikasi. Hanya saja, prediksi hasilnya menunjukkan sesuatu yang belum terjadi (mungkin terjadi di masa depan).

f. Klasifikasi

Dalam klasifikasi variabel, tujuan bersifat kategorik. Misalnya, kita akan mengklasifikasikan pendapatan dalam 3 kelas, yaitu mendapatkan tinggi, pendapatan sedang, dan pendapatan rendah.

g. Clustering

Clustering lebih kearah pengelompokan record, pengamatan, atau kasus dalam kelas yang memiliki kemiripan. Sebuah cluster adalah kumpulan record yang memiliki kemiripan satu dengan yang lain dan memiliki ketidak miripan dengan record-record dalam cluster yang lain.

h. Asosiasi

Mengidentifikasi hubungan antara berbagai peristiwa yang terjadi padasatu waktu. Pendekatan asosiasitersebut menekankan sebuah kelas masalah yang dicirikan dengan analisis keranjang pasar. 
Algoritma apriori adalah algoritma pengambilan data dengan aturan asosiatif (Association rule) untuk menentukan hubungan asosiatif suatu kombinasi item(Simbolon, 2019).

Berikut adalah langkah-langkah penyelesaian untuk algoritma apriori (Wahyuni et al., 2017) sebagai berikut :

a. Analisis Pola Frekuensi Tinggi

Tahap ini mencari kombinasi item yang memenuhi syarat minimum dari nilai support dalam data, yang dirumuskan sebagai berikut:

Support : $(A \cap B)=\frac{\sum \text { Transaksi yang mengandung } A \text { dan } B}{\sum \text { Transaksi }} * 100 \%$

Support adalah suatu ukuran yang menunjukkan seberapa besar tingkatdominasi suatu item atau itemset dari keseluruhantransaksi (Kurniawati et al., 2019).

b. Pembentukan aturan asosiatif

Setelah semua pola frekuensi tinggi ditemukan, selanjutnya adalah mencari aturan asosiatif yang memenuhi syarat minimum untuk confidence dengan mengitung confidenceaturan asosiatif $A->B$ dengan rumus sebagai berikut :

Confidence $=\frac{\sum \text { Transaksi yang mengandung A dan } B}{\sum \text { Transkasi Mengandung } A} * 100 \%$

Confidence adalah suatu ukuran yang menunjukkan hubungan antar dua item secarakonditional (Kurniawati et al., 2019).

\section{METODE PENELITIAN}

Penelitian adalah cara untuk mengembangkan pengetahuan dan memecahkan sebuah masalah atau menjawab pertanyaan-pertanyaan. Penelitian juga pada dasarnya merupakan cara ilmiah untuk mendapatkan data dengan tujuan dan kegunaan tertentu(Sudaryono,2019). Berikut pengumpulan data, Populasi dan Sampel Penelitian yang dilakukan oleh penulis :

1. Pengumpulan Data

Dalam tahap pengumpulan data dilakukan proses pengumpulan informasi yang dibutuhkan, dengan cara sebagai berikut :

a. Observasi Langsung

Pengumplan data yang dilakukan dengan pengamatan langsung ke perusahaan agar mendapatkan data dan informasi yang dibutuhkan untuk penelitian. Dalam hal ini, peneliti melakukan observasi langsung pada bagian pengelolaan aset, dimana melakukan pengamatan, mencari infomasi dan data mengenai data aset persediaan peralatan dan mesin khusus pada Sudin Perpustakaan dan Kearsipan Jakarta, yang nantinya data tersebut akan digunakan sebagai data olah dengan metode data mining didalam penelitian yang akan dilakukan.

b. Wawancara

Tahapan wawancara ini dilakukan dengan maksud agar mendapatkan lebih banyak informasi yang berkaitan dengan data yang akan diteliti oleh peneliti. Pada wawancara ini penulis melakukan sesi wawanara dengan Ibu Anna Maria Batubara selaku Kepala Sub Bidang Perencanaan di BPAD DKI Jakarta.

c. Penelitian Kepustakaan

Penelitian kepustakaan yang dilakukan oleh penulis yaitu dengan memperoleh dasardasar teori dari beberapa sumber untuk mendapatkan informasi yang lebih luas. Dari berbagai sumber seperti buku dan jurnal yang berkaitan dengan penelitian, bertujuan untuk mendapatkan landasan teori dan teknik dalam pengelolaan data mining menggunakan metode apriori dan informasi tambahan yang dapat membantu dalam kegiatan penelitian.

2. Populasi

Populasi adalah seluruh data yang menjadi perhatian kita dalam suatu ruang lingkup. Populasi bisa berupa manusia, produk, bahkan bisa berupa data (Ibrahim et al., 2018). Populasi dalam penelitian ini adalah peralatan dan mesin di Sudn Perpustakaan dan Kearsipan yang dikelola oleh Badan Pengeloaan Aset Daerah (BPAD) DKI Jakarta. 
IJSE - Indonesian Journal on Software Engineering, Vol.6, No.2, Desember 2020, 195-203

3. Sampel Penelitian

Sampel penelitian merupakan faktor penting yang perlu diperhatikan dalam penelitian yang akan dilakukan. Sampel penelitian mencerminkan dan menentukan seberapa jauh sampel tersebut bermanfaat dalam membuat kesimpulan dari penelitian.

4. Metode Apriori

Dalam melakukan penelitian ini penulis menggunakan metode Apriori untuk menentukan persediaan peralatan dan mesin

\section{HASIL DAN PEMBAHASAN} berikut:

Pembahasan mengenai langkah-langkah yang dilakukan dalam penelitian ini, sebagai

1. Data

Data yang diambil mengenai data pembelian Peralatan dan Mesin yang telah dibeli untuk persedian dan penggantian barang pada Sudin Perpustakaan dan Kearsipan, data didapatkan sebagai berikut:

a. Data Jenis Barang

Dari data yang ada terdapat beberapa jenis barang yang terdapat dengan jumlah kasus terbesar, jenis barang yang didapatkan ditampilkan dalam bentuk tabel di bawah ini:

Tabel 1. Jenis Barang

\begin{tabular}{|c|l|c|}
\hline No. & \multicolumn{1}{|c|}{ Nama Barang } & Inisial \\
\hline 1 & FILLING BESI/METAL & A \\
\hline 2 & MOBIL UNIT PERPUSTAKAAN KELILING & B \\
\hline 3 & KURSI BESI / METAL & C \\
\hline 4 & RAK BESI/METAL & D \\
\hline 5 & KURSI LIPAT & E \\
\hline 6 & P.C. UNIT (PERSONAL COMPUTER) & F \\
\hline 7 & ALAT PEMADAM/PORTABLE & G \\
\hline
\end{tabular}

b. Data Transaksi Pelaporan Peralatan dan Mesin

Data yang digunakan yaitu transaksi data aset pelaporan Peralatan dan Mesin selama satu tahun di tahun 2019.

Tabel 2. Data Transaksi Selama Satu Tahun di Tahun 2019

\begin{tabular}{|c|c|l|l|}
\hline No. & Kode.Reg & \multicolumn{1}{|c|}{ Item Nama Barang } \\
\hline 1 & 011019 & Felling Besi Metal \\
\hline 2 & 002019 & Mobil Unit Perpustakaan Keliling \\
\hline 3 & 000419 & Mobil Unit Perpustakaan Keliling dan Kursi Besi/Metal \\
\hline 4 & 590019 & Kursi Besi/Metal \\
\hline 5 & 610019 & Jursi Besi Metal dan Rak Besi/Metak \\
\hline 6 & 510019 & Kursi Lipat dan P.C Unit (Personal Computer) \\
\hline 7 & 130019 & P.C Unit (Personal Computer) \\
\hline 8 & 009019 & \\
\hline 9 & 005019 & Alat Pemadam/Portable \\
\hline 10 & 015019 & Felling Besi/Metal dan Alat Pemadam/Portable \\
\hline 11 & 017019 & $\begin{array}{l}\text { Felling Besi/Metal, Mobil Unit Perpustakaan Keliling dan Alat } \\
\text { Pemadam/Portable }\end{array}$ \\
\hline 12 & 030019 & Kursi Besi/Metal dan Kursi Lipat \\
\hline 13 & 031019 & Rak Besi/Metal \\
\hline 14 & 034019 & Rak Besi/Metal dan Kursi Lipat & \\
\hline
\end{tabular}




\begin{tabular}{|c|c|l|}
\hline No. & Kode.Reg & \\
\hline 15 & 035019 & \\
\hline 16 & 036019 & Kursi Besi/Metal dan P.C Unit (Personal Computer) \\
\hline 17 & 014019 & Mobil Unit Perpustakaan Keliling dan P.C Unit (Personal Computer) \\
\hline 18 & 051019 & Filling Besi/Metal dan Rak Besi/Metal \\
\hline 19 & 002019 & Alat Pemadam/Portable \\
\hline 20 & 004019 & Alat Pemadam/Portable \\
\hline 21 & 067019 & Filling Besi/Metal dan Rak Besi/Metal \\
\hline 22 & 069019 & Kursi Besi/Metal \\
\hline 23 & 070019 & Filling Besi/Metal dan Kursi Besi/Metal \\
\hline 24 & 196019 & Filling Besi/Metal dan Kursi Besi/Metal \\
\hline 25 & 000202 & Kursi Lipat \\
\hline 26 & 000022 & Mobil Unit Perpustakaan Keliling dan P.C Unit (Personal Computer) \\
\hline 27 & 000023 & Kursi Lipat dan P.C Unit (Personal Computer) \\
\hline 28 & 000024 & Filling Besi/Metal, Mobil Unit Perpustakaan Keliling dan P.C Unit \\
\hline 29 & 000026 & Kerosnal Computer) \\
\hline 30 & 000084 & Rak Besi/Metal dan Kursi Lipat \\
\hline 31 & 000086 & Mobil Unit Perpustakaan Keliling dan Kursi Lipat \\
\hline 32 & 000090 & Rak Besi/Metal dan Kursi Lipat \\
\hline 33 & 000093 & Filling Besi/Metal, Rak Besi/Metal dan Kursi Lipat \\
\hline 34 & 000162 & Filling Besi/Metal dan Rak Besi/Metal \\
\hline 35 & 000324 & Filling Besi/Metal, Rak Besi/Metal dan P.C Unit (Personal Computer) \\
\hline 36 & 000171 & Kursi Besi/Metal dan Kursi Lipat \\
\hline 37 & 000173 & Filling Besi/Metal dan Kursi Besi/Metal \\
\hline 38 & 000174 & P.C Unit (Personal Computer) \\
\hline 39 & 235019 & Kursi Lipat \\
\hline 40 & 246019 & Rak Besi/Metal \\
\hline & &
\end{tabular}

c. Data Dalam Bentuk Tabulasi

Tabel data dibuat dalam bentuk tabel tabulasi sehingga memudahkan perhitunggan dan pengelolahan data mining dengan banyak data sebesar 40 data.

Tabel 3. Tabulasi Data Peralatan dan Mesin

\begin{tabular}{|c|c|c|c|c|c|c|c|}
\hline NO. & A & $\mathrm{B}$ & $\mathrm{C}$ & $\mathrm{D}$ & $\mathrm{E}$ & $\mathrm{F}$ & $\mathrm{G}$ \\
\hline 1 & 1 & 0 & 0 & 0 & 0 & 0 & 0 \\
\hline 2 & 0 & 1 & 0 & 0 & 0 & 0 & 0 \\
\hline 3 & 0 & 1 & 1 & 0 & 0 & 0 & 0 \\
\hline 4 & 0 & 0 & 1 & 0 & 0 & 0 & 0 \\
\hline 5 & 0 & 0 & 1 & 1 & 0 & 0 & 0 \\
\hline 6 & 0 & 0 & 0 & 0 & 1 & 1 & 0 \\
\hline 7 & 0 & 0 & 0 & 0 & 0 & 1 & 0 \\
\hline 8 & 0 & 0 & 0 & 0 & 0 & 0 & 0 \\
\hline 9 & 0 & 0 & 0 & 0 & 0 & 0 & 1 \\
\hline 10 & 1 & 0 & 0 & 0 & 0 & 0 & 1 \\
\hline 11 & 1 & 1 & 0 & 0 & 0 & 0 & 1 \\
\hline
\end{tabular}




\begin{tabular}{|c|c|c|c|c|c|c|c|}
\hline NO. & $\mathrm{A}$ & $\mathrm{B}$ & $\mathrm{C}$ & $\mathrm{D}$ & $\mathrm{E}$ & $\mathrm{F}$ & $\mathrm{G}$ \\
\hline 12 & 0 & 0 & 1 & 0 & 1 & 0 & 0 \\
\hline 13 & 0 & 0 & 0 & 1 & 0 & 0 & 0 \\
\hline 14 & 0 & 0 & 0 & 1 & 1 & 0 & 0 \\
\hline 15 & 0 & 0 & 0 & 0 & 0 & 0 & 0 \\
\hline 16 & 0 & 0 & 1 & 0 & 0 & 1 & 0 \\
\hline 17 & 0 & 1 & 0 & 0 & 0 & 1 & 0 \\
\hline 18 & 1 & 0 & 0 & 1 & 0 & 0 & 0 \\
\hline 19 & 0 & 0 & 0 & 0 & 0 & 0 & 1 \\
\hline 20 & 0 & 0 & 0 & 0 & 0 & 0 & 1 \\
\hline 21 & 1 & 0 & 0 & 1 & 0 & 0 & 0 \\
\hline 22 & 0 & 0 & 1 & 0 & 0 & 0 & 0 \\
\hline 23 & 1 & 0 & 1 & 0 & 0 & 0 & 0 \\
\hline 24 & 1 & 0 & 1 & 0 & 0 & 0 & 0 \\
\hline 25 & 0 & 0 & 0 & 0 & 1 & 0 & 0 \\
\hline 26 & 0 & 1 & 0 & 0 & 0 & 1 & 0 \\
\hline 27 & 0 & 0 & 0 & 0 & 1 & 1 & 0 \\
\hline 28 & 1 & 1 & 0 & 0 & 0 & 1 & 0 \\
\hline 29 & 0 & 0 & 0 & 0 & 1 & 1 & 0 \\
\hline 30 & 0 & 0 & 0 & 1 & 1 & 0 & 0 \\
\hline 31 & 0 & 1 & 0 & 0 & 1 & 0 & 0 \\
\hline 32 & 0 & 0 & 0 & 1 & 1 & 0 & 0 \\
\hline 33 & 1 & 0 & 0 & 1 & 1 & 0 & 0 \\
\hline 34 & 1 & 0 & 0 & 1 & 0 & 0 & 0 \\
\hline 35 & 1 & 0 & 0 & 1 & 0 & 1 & 0 \\
\hline 36 & 0 & 0 & 1 & 1 & 0 & 0 & 0 \\
\hline 37 & 1 & 0 & 1 & 0 & 0 & 0 & 0 \\
\hline 38 & 0 & 0 & 0 & 0 & 0 & 1 & 0 \\
\hline 39 & 0 & 0 & 0 & 0 & 1 & 0 & 0 \\
\hline 40 & 1 & 0 & 0 & 0 & 0 & 0 & 0 \\
\hline $\mathrm{JML}$ & $\mathbf{1 3}$ & $\mathbf{7}$ & $\mathbf{1 0}$ & $\mathbf{1 1}$ & $\mathbf{1 1}$ & $\mathbf{1 0}$ & $\mathbf{5}$ \\
\hline
\end{tabular}

d. Perhitungan Algoritma Apriori

1) Menentukan Nilai $\Phi$ dan Mencari Data K1

Tabel IV. 3 digunakan untuk melakukan perhitungan dengan ditentukan nilai $\Phi=5$, sehingga diketahui nilai dari data diatas yang memenuhi $\Phi$ untuk data $\mathrm{k} 1$ (satu unsur), yaitu $(A),(B),(C),(D),(E),(F),(G)$.

2) Mencari Data K2 dan Frekuen 2 Item Set

Data k2 didapatkan dari himpunan k1 yang nantinya akan terbentuk himpunan dengan kandidat sebagai berikut:

$(A, B),(A, C),(A, D),(A, E),(A, F),(A, G),(B, C),(B, D),(B, E),(B, F),(B, G),(C, D),(C, E),(C, F),(C, G),($ $D, E),(D, F),(D, G),(E, F),(E, G),(F, G)$. 

berikut:

Sehingga calon 2 item set digambarakan dalam Tabel 4. Data Frekuen 2 Item Set sebagai

Tabel 4. Data Frekuen 2 Item Set

\begin{tabular}{|c|c|c|}
\hline No. & 2 ItemSet & Support Count \\
\hline 1 & $\mathrm{~A}, \mathrm{~B}$ & 2 \\
\hline 2 & $\mathrm{~A}, \mathrm{C}$ & 3 \\
\hline 3 & $\mathrm{~A}, \mathrm{D}$ & 5 \\
\hline 4 & $\mathrm{~A}, \mathrm{E}$ & 0 \\
\hline 5 & $\mathrm{~A}, \mathrm{~F}$ & 2 \\
\hline 6 & $\mathrm{~A}, \mathrm{G}$ & 0 \\
\hline 7 & $\mathrm{~B}, \mathrm{C}$ & 1 \\
\hline 8 & $\mathrm{~B}, \mathrm{D}$ & 0 \\
\hline 9 & $\mathrm{~B}, \mathrm{E}$ & 1 \\
\hline 10 & $\mathrm{~B}, \mathrm{~F}$ & 3 \\
\hline 11 & $\mathrm{~B}, \mathrm{G}$ & 1 \\
\hline 12 & $\mathrm{C}, \mathrm{D}$ & 2 \\
\hline 13 & $\mathrm{C}, \mathrm{E}$ & 1 \\
\hline 14 & $\mathrm{C}, \mathrm{F}$ & 1 \\
\hline 15 & $\mathrm{C}, \mathrm{G}$ & 0 \\
\hline 16 & $\mathrm{D}, \mathrm{E}$ & 4 \\
\hline 17 & $\mathrm{D}, \mathrm{F}$ & 1 \\
\hline 18 & $\mathrm{D}, \mathrm{G}$ & 0 \\
\hline 19 & $\mathrm{E}, \mathrm{F}$ & 3 \\
\hline 20 & $\mathrm{E}, \mathrm{G}$ & 0 \\
\hline 21 & $\mathrm{~F}, \mathrm{G}$ & 0 \\
\hline & & \\
\hline
\end{tabular}

Dari tabel frekuen 2 item set diatas didapatkan jumlah yang lebih besar atau sama dengan jumlah nilai $\Phi$ didapatkan satu kandidat untuk penentuan aturan yaitu $(A, D)$ dengan nilai count 5 dimana nilai tersebut sama dengan nilai $\Phi$, dari hasil 2 item yang memenuhi syarat nilai $\Phi$ maka untuk proses frekuen 3 item set dan frekuen selanjutnya tidak ada karena tidak memenuhi nilai yang telah ditetapkan yaitu dengan nilai $\Phi=5$.

3) Mencari Rule yang Digunakan

Rules yang dipakai adalah if $\boldsymbol{x}$ then $\boldsymbol{y}, \mathrm{x}$ merupakan antecedent dan $y$ adalah consequent. Dimana dalam kasus ini bentuk aturanya yaitu, if reporting of purchasing goods $\boldsymbol{x}$ then reporting goods $\boldsymbol{y}$.

4) Menentukan Nilai Antecedent (ss-s)dan Consequent (s)

Setelah didapatkan model aturan yang telah ditentukan ditahapan sebelumnya, maka dibentuk nilainya dengan melihat himpunan 2 item set, sehingga dapat disusun sebagai berikut:

Rules $(A, D)$ :

a) Jika (ss-s) $=$ A, Jika s $=\mathrm{D}$, Maka $\rightarrow$ If reporting of purchasing goods A then reporting goods D.

b) Jika (ss-s) $=\mathrm{D}$, Jika $\mathrm{s}=\mathrm{A}$, Maka $\rightarrow$ If reporting of purchasing goods $\mathrm{D}$ then reporting goods A.

5) Menghitung Nilai Support dan Confidence

Telah didapatkan 2 rules kandidatsehingga perhitungan support dan confidence seperti dibawah ini:

\section{Support:}

a) A and D: 
$5 / 40 \times 100 \%=12,5 \%$

b) $\mathrm{D}$ and $\mathrm{A}$.

$5 / 40 \times 100 \%=12,5 \%$

Confidence:

a) $\mathrm{A}$ and $\mathrm{D}$ :

$5 / 13 \times 100 \%=38,46 \%$

b) $\mathrm{D}$ and $\mathrm{A}$.

$5 / 10 \times 100 \%=45,45 \%$

6) Mencri Spportda Confdence dengan nilai yang telah ditentukan

Untuk mencari nilai support dan confidence yang nantinya untuk menentukan rule yang akan digunakan, dengan mencari nilai support sebesar $12 \%$ ke atas dan confidence dengan nilai $40 \%$ ke atas yang telah dilakukan perhitungan di tahapan sebelumnya hingga terbentuk seperti tabel dibawah ini:

Tabel 1. Hasil Support dan Confidence Sesuai Dengan Nilai yang Ditetapkan

\begin{tabular}{|c|c|c|}
\hline Rules & Support & Confidence \\
\hline $\begin{array}{c}\text { If reporting of purchasing goods A } \\
\text { then reporting goods D }\end{array}$ & $12,5 \%$ & $38,46 \%$ \\
\hline $\begin{array}{c}\text { If reporting of purchasing goods D } \\
\text { then reporting goods A. }\end{array}$ & $12,5 \%$ & $45,45 \%$ \\
\hline
\end{tabular}

7) Hasil Perhitungan

Setelah didapat nilai support dan confidence yang sesuai dengan nilai yang ditetapkan, kemudian menentukan hasil dengan memilih satu nilai paling besar untuk dijadikan rule yang nantinya akan digunakan dalam penentuan pembelian barang untuk persedian Barang dan Mesin pada Sudin Perpustakaan dan Kearsipan Jakarta Pusa

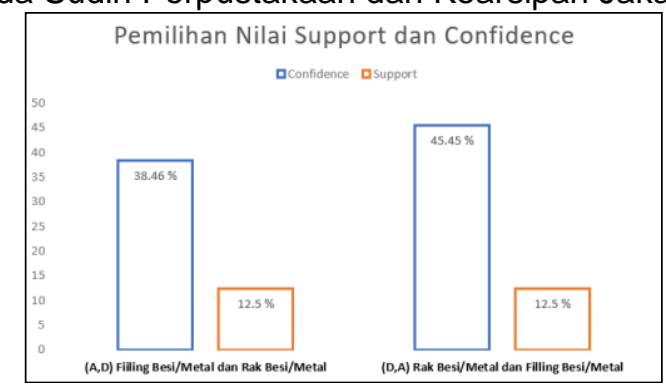

Gambar 1. Grafik Pemilihan Nilai Support dan Confidence

Berdasarkan gambar 1 didapatkan hasil $(\mathrm{D}, \mathrm{A})$ dengan if reporting of purchasing goods $D$ then reporting goods $A$. Sehingga aturanya yang dapat digunakan yaitu :

Jika terjadi pelaporan pembelian barang baru untuk persediaan barang Rak Besi/Metal maka akan terdapat pembelian juga untuk Filling Besi/Metal dengan nilai support sebesar $12,5 \%$ dan confidence sebesar $45,45 \%$.

\section{E. KESIMPULAN}

Dari penelitian yang telah dilakukan, maka kesimpulan yang dapat diambil pada penelitian sebagai berikut :

a. Data mining dengan metode Apriori membantu mengetahui persediaan barang dan mesin yang dibutuhkan Tahun 2019 di Sudin Perpustakaan dan Kearsipan, agar dilakukan penggantian barang yang dibutuhkan tiap tahunnya.

b. Jika terjadi pelaporan pembelian barang baru untuk persediaan barang Rak Besi/Metal maka akan ada pembelian juga untuk Filling Besi/Metal. Pembelian ini didapat karena memiliki nilai support dan confidence yang tertinggi.

Dari hasil penelitian yang telah dilakukan peneliti, maka saran yang dari peneliti sebagai berikut : 
a. Penerapan Data mining yang dilakukan perlu ditingkatkan lagi. Dapat dilakukan dengan metode lain agar mendapat perbandingan dan hasil yang akurat.

b. Jangka waktu yang digunakan bisa lebih dari satu tahun agar mendapatkan informasi data yang lebih akurat.

\section{REFERENSI}

Azwar, A. (2015). Algorithma Apriori Untuk Mendapatkan Perilaku Konsumen Dalam Pembelian Barang. Sains Dan Informatika, 1, 45-59.

Budiantara, A. F., \& Budihartanti, C. (2020). Implementasi Data Mining Dalam Manajemen Inventory Pada Pt . Mastersystem Infotama Menggunakan Metode Algoritma Apriori. 7(1).

Ependi, U., \& Putra, A. (2019). Solusi Prediksi Persediaan Barang Dengan Menggunakan Algoritma Apriori (Studi Kasus: Regional Part Depo Auto 2000 Palembang). Jurnal Edukasi Dan Penelitian Informatika (Jepin), 5(2), 139. Https://Doi.Org/10.26418/Jp.V5i2.32648

Kennedi Tampubolon, Hoga Saragih, B. R. (1966). Implementasi Data Mining Algoritma Apriori Pada Sistem Persediaan Alat-Alat Kesehatan. Proceedings Of The Prehistoric Society, 32, 73-85. Https://Doi.Org/10.1017/S0079497x00014341

Kurniawati, L., Kusuma, A. E., \& Dewansyah, B. (2019). Implementasi Algoritma Apriori Untuk Menentukan Persediaan Spare Part Compressor. Computer Engineering, Science And System Journal, 4(1), 6. Https://Doi.Org/10.24114/Cess.V4i1.11303

Simbolon, P. H. (2019). Implementasi Data Mining Pada Sistem Persediaan Barang Menggunakan Algoritma Apriori ( Studi Kasus: Srikandi Cash Credit Elektronic Dan Furniture ). Jurnal Riset Komputer, 6(4), 401-406.

Wahyuni, S., Suherman, \& Harahap, Lumalo Portibi. (2017). Implementasi Data Mining Dalam Memprediksi Stok Barang Menggunakan Algoritma Apriori. Prosiding Sintak 2017, 2(2), $31-$ 39.

Witama, M. N. (2019). Perancangan Aplikasi Pengelolaan Aset Barang Inventaris Sdn Makasar 05 Pagi Jakarta Timur. 3(3). 